American Journal of Applied Sciences 4(5): 257-263, 2007

ISSN 1546-9239

(C) 2007 Science Publications

\title{
Environmental Assessment of a Diesel Engine Under Variable Stroke Length and Constant Compression Ratio
}

\author{
${ }^{1}$ Jehad A. A. Yamin and ${ }^{2}$ Eyad S. M. Abu-Nameh \\ ${ }^{1}$ Department of Mechanical Engineering, Faculty of Engineering and Technology \\ University of Jordan, Amman 11942, Jordan \\ ${ }^{2}$ Department of Basic Science, Prince Abdullah Bin Ghazi Faculty of Science and Information \\ Technology, Al-Balqa Applied University, P.O. box 7272 Al-Salt 19117, Jordan
}

\begin{abstract}
In the light of the energy crisis and the stringent environmental regulations, diesel engines are offering good hope for automotive vehicles. However, lot of work is needed to reduce the diesel exhaust emissions and give the way for full utilization of the diesel fuel's excellent characteristics. This paper presents a theoretical study on the effect of variable stroke length technique on the emissions of a four-stroke, water-cooled direct injections diesel engine with the help of experimentally verified computer software designed mainly for diesel engines. The emission levels were studied over the speed range (1000 rpm to $3000 \mathrm{rpm})$ and stroke lengths $(120 \mathrm{~mm}$ to $200 \mathrm{rpm})$ and were compared with those of the original engine design. The simulation results clearly indicate the advantages and utility of variable stroke technique in the reduction of the exhaust emission levels. A reduction of about $10 \%$ to $75 \%$ was achieved for specific particulate matter over the entire speed range and bore-to-stroke ratio studied. Further, a reduction of about $10 \%$ to $59 \%$ was achieved for the same range. As for carbon dioxide, a reduction of $0 \%$ to $37 \%$ was achieved. On the other hand, a less percent change was achieved for the case of nitrogen dioxide and nitrogen oxides as indicated by the results. This study clearly shows the advantage of VSE over fixed stroke engines. This study showed that the variable stroke technique proved a good way to curb the diesel exhaust emissions and hence helped making these engines more environmentally friendly.
\end{abstract}

Keywords: Variable stroke engine, variable displacement engine, diesel engine exhaust, diesel engine simulation, diesel exhaust reduction

\section{INTRODUCTION}

Traffic management, access to major cities, public transport policy and health-related emissions are significant priorities in Jordan and in many other parts of the world. Diesel engine has been the preferred power source for public vehicles, for many years. Most recently, especially after the incidence in the gulf region, the Jordanian government has become more interested to increase the number of Diesel vehicles on the road. This is because of its economy and to reduce the energy bill on the government. However, there has been a growing concern over the impact of vehicle emissions in general. For this purpose, the Jordanian government has decided to make it mandatory for all types of Diesel vehicles to put a Diesel Filter (DPF or CDPF) to try to curb the increasing levels of exhaust pollution.
Reviewing the literature, it is noted that during recent years, extensive research was conducted in the field of heavy-duty diesel engines, which resulted in significant improvement to the engine's performance and emission levels. Research broadly concentrated on two areas (1) fuel improvement and (2) engine design modification. As for the first area of research, great deal of work was conducted with the aim of either finding a replacement for diesel fuel or enhancing the properties of the present diesel fuel.

Among the alternatives studied were Di-MethyleEther $^{[1]}$, Jojoba oil ${ }^{[2]}$, vegetable oil ${ }^{[3]}$, coconut oil ${ }^{[4]}$ and many other alternatives both as pure engine fuel and as supplementary/additive to diesel fuel. Further, water-indiesel emulsion ${ }^{[5]}$ was also studied and proved to be very effective in cutting down the exhaust emissions of the diesel engines. This area of research resulted in improving certain aspects of the engine performance e.g. some of the exhaust emissions were reduced like soot, HC, smoke level, while others were increased like NOx. 
Am. J. Applied Sci., 4(5): 257-263, 2007

The second area of research, concentrated on the introduction of engine modification to the existing design. The use of the variable stroke engine (VSE) concept has been gaining lots of interest and was also subjected to investigations encouraged by the success story of the Saab Company. Variable stroke engines are gaining attention by researchers and automobile manufactures for their fuel economy advantage. In fixed stroke engines, load variation is balanced out by throttling of the intake fuel-air mixture. This approach leaves the pumping and frictional losses unchanged since the stroke remained constant. However, in variable stroke engine these losses are reduced since a short stroke is used for low engine load and longer strokes are used for high engine loads. Siegla and Siewert ${ }^{[6]}$ and Siewert ${ }^{[7]}$ reported a fuel economy approaching $20 \%$ for variable stroke engines over fixed stroke engines. This study focuses on a patented variable stroke engine mechanism by Freudenstein and Maki $^{[8]}$. A full displacement analysis is performed where the piston displacement and connecting rod angle are related to the crank angle for several stroke length arrangements. A simulation model for the engine was developed with the different power and efficiency characteristics are computed and presented for different stroke lengths and the corresponding compression ratios. Yamin and $\operatorname{Dado}^{[9]}$ also investigated, theoretically, the effect of variable stroke mechanism on the gasoline-engine performance and showed that the engine performance improves with this new design. Further, Filipi et al. ${ }^{[10]}$ theoretically investigated the effect of varying the stroke length on a homogeneouscharge engine's combustion, heat transfer and efficiency using gasoline as fuel. Similar studies on the effect of bore-to-stroke ratio on engine performance were also done by Abenavoli et al. ${ }^{[11,12]}$. All of them used gasoline in their work.

This study presents a first attempt to study the effect of implementing this technique on the compresson ignition engines, to study its effect on the exhaust emissions. It will try to shed some light on the effect of varying the stroke length (at constant compression ratio) on the exhaust emission levels of diesel engines using this new technique.

The study: This theoretical study was conducted using the Diesel-RK software ${ }^{[13]}$ since executing this work experimentally requires highly sophisticated setup which is not available to the author. In this study, the stroke length and engine speed were varied as shown in Table 1, while the injection timing and compression ratio were kept constant at 20 degrees before top dead center and 15:1 respectively. The cylinder diameter was
Table 1: Stroke length, clearance and bore-to-stroke length for several stroke lengths

\begin{tabular}{lcr}
\hline $\begin{array}{l}\text { Stroke Length (S) mm } \\
\text { Ratio }\end{array}$ & Clearance Height mm & Bore/Stroke \\
\hline 120 & 8.571 & 1.2500 \\
140 & 10.000 & 1.0170 \\
160 & 11.428 & 0.9375 \\
180 (Basic Design) & 12.857 & 0.8333 \\
200 & 14.285 & 0.7500 \\
\hline
\end{tabular}

also kept constant at $150 \mathrm{~mm}$. For further details see appendix (A). The engine speed was varied between $1000 \mathrm{rpm}$ to $3000 \mathrm{rpm}$.

\section{Brief about some automotive emissions ${ }^{[14]}$}

Carbon monoxide (CO): Carbon monoxide, a colorless, odorless, poisonous gas, is generated in an engine when it is operated with a fuel-rich equivalence ratio. When there is not enough oxygen to convert all carbon to $\mathrm{CO}_{2}$, some fuel does not get burned and some carbon ends up as CO. Not only is CO considered an undesirable emission, but it also represents lost chemical energy that was not fully utilized in the engine. $\mathrm{CO}$ is a fuel that can be combusted to supply additional thermal energy:

$\mathrm{CO}+1 / 2 \mathrm{O}_{2} \rightarrow \mathrm{CO}_{2}+$ heat

Maximum $\mathrm{CO}$ is generated when an engine runs rich, such as when starting or when accelerating. Even when the intake air-fuel mixture is stoichiometric or lean, some $\mathrm{CO}$ will be generated in the engine. Poor mixing, local rich regions and incomplete combustion will create some $\mathrm{CO} . \mathrm{Cl}$ engines that operate in a lean manner overall generally have very low $\mathrm{CO}$ emissions.

Oxides of nitrogen (NOx): Exhaust gases of an engine can have up to $2000 \mathrm{ppm}$ of oxides of nitrogen. Most of this will be nitrogen oxide (NO), with a small amount of nitrogen dioxide (NOx) and traces of other nitrogenoxygen combinations. These are all grouped together as NOx (or $\mathrm{NO}_{\mathrm{x}}$, with $\mathrm{x}$ representing some suitable number). NOx is a very undesirable emission and regulations that restrict the allowable amount continue to become more stringent. Released NOx reacts in the atmosphere to form ozone and is one of the major causes of photochemical smog.

NOx is created mostly from nitrogen in the air. Nitrogen can also be found in fuel blends, which may contain trace amounts of $\mathrm{NH}_{3}, \mathrm{NC}$ and $\mathrm{HCN}$, but this would contribute only to a minor degree. There are a number of possible reactions that form NO, all of which are probably occurring during the combustion process and immediately after. These include but are not limited to,

$\mathrm{O}+\mathrm{N}_{2} \rightarrow \mathrm{NO}+\mathrm{N}$ 
Am. J. Applied Sci., 4(5): 257-263, 2007

$\mathrm{N}+\mathrm{O}_{2} \rightarrow \mathrm{NO}+\mathrm{O}$

$\mathrm{N}+\mathrm{OH} \rightarrow \mathrm{NO}+\mathrm{H}$

$\mathrm{NO}$, in turn, can then further react to form NOx by various means, including the following:

$\mathrm{NO}+\mathrm{H}_{2} \mathrm{O} \rightarrow \mathrm{NO}_{2}+\mathrm{H}_{2}$

$\mathrm{NO}+\mathrm{O}_{2} \rightarrow \mathrm{NO}_{2}+\mathrm{O}$

Atmospheric nitrogen exists as a stable diatomic molecule at low temperatures and only very small trace amounts of oxides of nitrogen are found. However, at the very high temperatures that occurs in the combustion chamber of an engine, some diatomic nitrogen $\left(\mathrm{N}_{2}\right)$ breaks down to monatomic nitrogen $(\mathrm{N})$, which is reactive:

$\mathrm{N}_{2} \rightarrow 2 \mathrm{~N}$

Chemical equilibrium tables in the show that the chemical equilibrium constant for the above equation (2) is highly dependent on temperature, with a much more significant amount of $\mathrm{N}$ generated in the 2500$3000 \mathrm{~K}$ temperature range that can exist in an engine. Other gases that are stable at low temperatures, but become reactive and contribute to the formation of NOx at high temperatures, include oxygen and water vapor, which break down as follows:

$\mathrm{O}_{2} \rightarrow 2 \mathrm{O}$

$\mathrm{H}_{2} \mathrm{O} \rightarrow \mathrm{OH}+1 / 2 \mathrm{H}_{2}$

Examination of chemical equilibrium tables and more elaborate chemical equilibrium constant tables found in chemistry handbooks show that chemical equations $(4 \& 5)$ all react much further to the right as high combustion chamber temperatures are reached. The higher the combustion reaction temperature, the more diatomic nitrogen, $\mathrm{N}_{2}$, will dissociate to monatomic nitrogen, $\mathrm{N}$ and the more $\mathrm{NOx}$ will be formed. At low temperatures, very little NOx is created.

Although maximum flame temperature will occur at a stoichiometric air-fuel ratio $(\phi=1)$, experiments show that maximum NOx is formed at a slightly lean equivalence ratio of about $\phi=0.95$. At this condition, the flame temperature is still very high and in addition, there is an excess of oxygen that can combine with the nitrogen to form various oxides.

In addition to its dependence on temperature, the formation of NOx depends on pressure, air-fuel ratio and combustion time within the cylinder, chemical reactions not being instantaneous. Experiments also show that NOx is reduced in modern engines with fastburn combustion chambers. The amount of NOx generated also depends on the location within the combustion chamber. The highest concentration is formed around the spark plug, where the highest temperatures occur. Because they generally have higher compression ratios and higher temperatures and pressure, $\mathrm{CI}$ engines with divided combustion chambers and indirect injection (IDI) tend to generate higher levels of NOx.

Particulates: The exhaust of CI engines contains solid carbon soot particles that are generated in the fuel-rich zones within the cylinder during combustion. These are seen as exhaust smoke and are an undesirable odorous pollution. Maximum density of particulate emissions occurs when the engine is under load at WOT. At this condition, maximum fuel is injected to supply maximum power, resulting in a rich mixture and poor fuel economy. This can be seen in the heavy exhaust smoke emitted when a truck or rail-road locomotive accelerates up a hill or from a stop.

Soot particles are clusters of solid carbon spheres. These spheres have diameters from $10 \mathrm{~nm}$ to $80 \mathrm{~nm}(1$ $\left.\mathrm{nm}=10^{-9} \mathrm{~m}\right)$, with most within the range of $15-30 \mathrm{~nm}$. The spheres are solid carbon with $\mathrm{HC}$ and traces of other components absorbed on the surface.

Carbon spheres are generated in the combustion chamber in the fuel-rich zones where there is not enough oxygen to convert all carbon to COs:

$\mathrm{C}_{\mathrm{x}} \mathrm{H}_{\mathrm{y}}+\mathrm{z} \mathrm{O}_{2} \rightarrow \mathrm{a} \mathrm{CO} \mathrm{CO}_{2}+\mathrm{b} \mathrm{H}_{2} \mathrm{O}+\mathrm{c} \mathrm{CO}+\mathrm{d} \mathrm{C}(\mathrm{s})$

Then, as turbulence and mass motion continue to mix the components in the combustion chamber, most of these carbon particles find sufficient oxygen to further react and are consumed to $\mathrm{CO}_{2}$ :

$\mathrm{C}(\mathrm{s})+\mathrm{O} 2 \rightarrow \mathrm{CO}_{2}$

Over $90 \%$ of carbon particles originally generated within an engine are thus consumed and never get exhausted. If $\mathrm{Cl}$ engines were to operate with an overall stoichiometric air-fuel mixture, instead of the overall lean mixture they do operate with, particulate emissions in the exhaust would far exceed acceptable levels.

Up to about $25 \%$ of the carbon in soot comes from lubricating-oil components, which vaporize and then react during combustion. The rest comes from the fuel and amounts to $0.2-0.5 \%$ of the fuel. Because of the high compression ratios of CI engines, a large expansion occurs during the power stroke and the gases within the cylinder are cooled by expansion cooling to a relatively low temperature. This causes the remaining high-boiling-point components found in the fuel and lubricating oil to condense on the surface of the carbon soot particles. This absorbed portion of the soot particles is called the soluble organic fraction (SOF) and the amount is highly dependent on cylinder temperature. At light loads, cylinder temperatures are reduced and can drop to as low as $200^{\circ} \mathrm{C}$ during final expansion and exhaust blowdown. Under these conditions, SOF can be as high as $50 \%$ of the total mass of soot. Under other operating conditions when temperatures are not so low, very little condensing 
occurs and SOF can be as low as 3\% of total soot mass. SOF consists mostly of hydrocarbon components with some hydrogen, $\mathrm{SO}_{2}, \mathrm{NO}, \mathrm{NO}_{2}$ and trace amounts of sulfur, zinc, phosphorus, calcium, iron, silicon and chromium. Diesel fuel contains sulfur, calcium, iron, silicon and chromium, while lubricating-oil additives contain zinc, phosphorus and calcium.

Particulate generation can be reduced by engine design and control of operating conditions, but quite often this will create other adverse results. If the combustion time is extended by combustion chamber design and timing control, particulate amounts in the exhaust can be reduced. Soot particles originally generated will have a greater time to be mixed with oxygen and combusted to $\mathrm{CO}_{2}$. However, a longer combustion time means a high cylinder temperature and more NOx generated. Dilution with EGR lowers NOx emissions, but increases particulate and $\mathrm{HC}$ emissions. Higher injection pressure gives a finer droplet size, which reduces $\mathrm{HC}$ and particulate emissions, but increases cylinder temperature and NOx emissions. Engine management systems are programmed to minimize $\mathrm{NOx}, \mathrm{HC}, \mathrm{CO}$ and particulate emissions by controlling ignition timing, injection pressure, injection timing and/or valve timing. Obviously, compromise is necessary. In most engines, exhaust particulate amounts cannot be reduced to acceptable levels solely by engine design and control.

Carbon dioxide $\left(\mathbf{C O}_{2}\right)$ : At moderate levels of concentration, carbon dioxide is not considered an air pollutant. However, it is considered a major greenhouse gas and at higher concentrations, is a major contributor to global warming. $\mathrm{CO}_{2}$ is a major component of the exhaust in the combustion of any hydrocarbon fuel. Because of the growing number of motor vehicles, along with more factories and other sources, the amount of carbon dioxide in the atmosphere continues to growAt upper elevations in the atmosphere, this higher concentration of carbon dioxide, along with other greenhouse gases, creates a thermal radiation shield, This shield reduces the amount of thermal radiation energy allowed to escape from the earth, raising slightly the average earth temperature. The most efficient way of reducing the amount of $\mathrm{CO}_{2}$ is to burn less fuel (i.e., use engines with higher thermal efficiency).

\section{RESULTS AND DISCUSSION}

The emissions studied were the carbon dioxide, nitrogen oxides, nitrogen dioxide, particulate matter and Bosch smoke number. With the above theory in hand the results of this study can be explained.

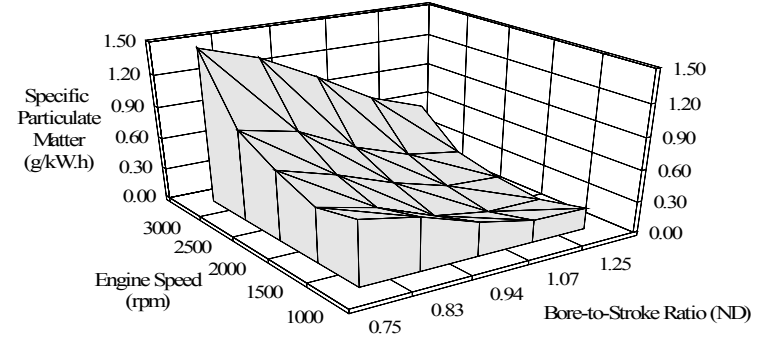

Fig. 1: Variation of $\mathrm{PM}$ with $\mathrm{B} / \mathrm{S}$ ratio at different engine speeds

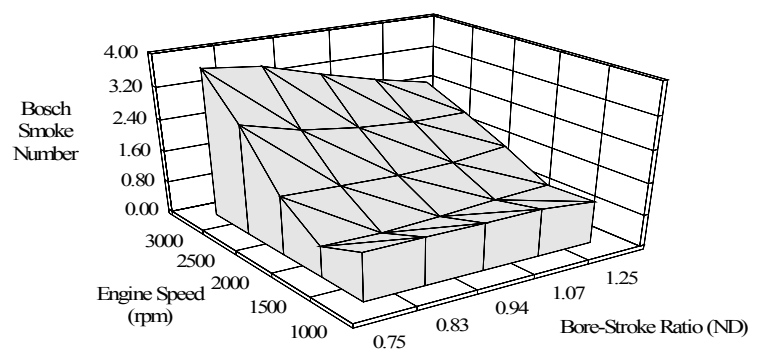

Fig. 2: Variation of Bosch Smoke Number with B/S ratio at different engine speeds

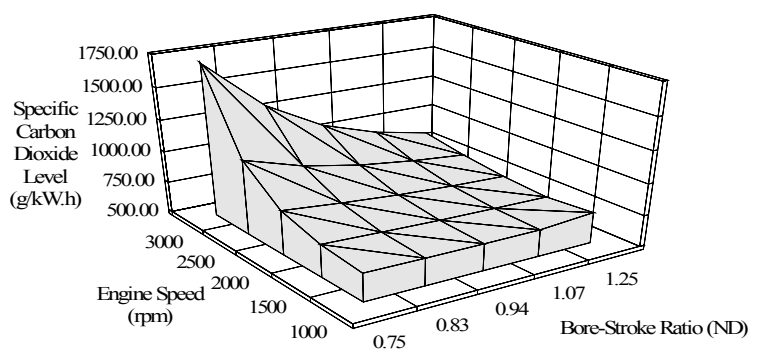

Fig. 3: Variation of specific carbon dioxide with $\mathrm{B} / \mathrm{S}$ ratio at different engine speeds

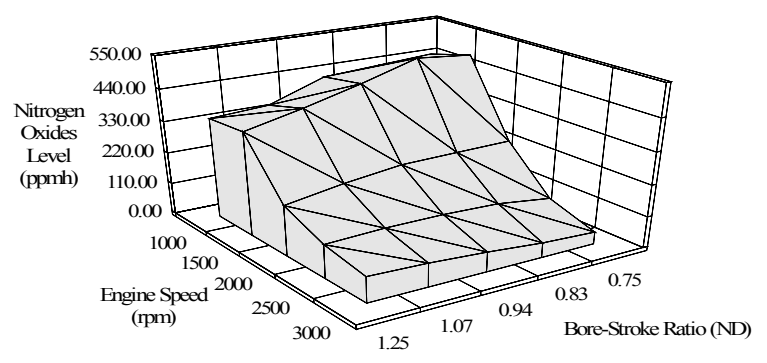

Fig. 4: Variation of wet nitric oxides with $\mathrm{B} / \mathrm{S}$ ratio at different engine speeds

The results of the study are presented in Fig. 1-9. The study was conducted with basic aim to compare the performance of the engine before modifications with that of the engine with variable displacement technique at different engine speeds. 
Am. J. Applied Sci., 4(5): 257-263, 2007

Table 2: The relative change in parameters with change in $\mathrm{B} / \mathrm{S}$ ratios at $3000 \mathrm{rpm}$

\begin{tabular}{llllll}
\hline & $-11 \%$ & Original B/S ratio & $+13 \%$ & $+22 \%$ & $+50 \%$ \\
\hline PM & $+75 \%$ & $0 \%$ & $-43 \%$ & $-73 \%$ & $-82 \%$ \\
BSN & $+17 \%$ & $0 \%$ & $-22 \%$ & $-48 \%$ & $-59 \%$ \\
$\mathrm{CO}_{2}$ & $+39 \%$ & $0 \%$ & $-19 \%$ & $-30 \%$ & $-37 \%$ \\
$\mathrm{NO}_{2}$ & $+17.15 \%$ & $0 \%$ & $-4.65 \%$ & $-0.25 \%$ & $-4.95 \%$ \\
$\mathrm{NO}_{x}$ & $-16.55 \%$ & $0 \%$ & $+18.3 \%$ & $+44.15 \%$ & $+51.7 \%$ \\
\hline
\end{tabular}

Table 3: The relative change in parameters with change in $\mathrm{B} / \mathrm{S}$ ratios at $1500 \mathrm{rpm}$

\begin{tabular}{llllll}
\hline & $-11 \%$ & Original B/S ratio & $+13 \%$ & $+22 \%$ & $+50 \%$ \\
\hline PM & $-4.15 \%$ & $0 \%$ & $-6.75 \%$ & $-48.35 \%$ & $-63.65 \%$ \\
$\mathrm{BSN}$ & $-4.75 \%$ & $0 \%$ & $-3.65 \%$ & $-38.9 \%$ & $-53.65 \%$ \\
$\mathrm{CO}_{2}$ & $+2 \%$ & $0 \%$ & $-2.25 \%$ & $-4.27 \%$ & $-5.35 \%$ \\
$\mathrm{NO}_{2}$ & $+6.15 \%$ & $0 \%$ & $-10.55 \%$ & $-11.15 \%$ & $-5.7 \%$ \\
$\mathrm{NO}_{\mathbf{x}}$ & $+4.05 \%$ & $0 \%$ & $-8.5 \%$ & $-7.65 \%$ & $-0.28 \%$ \\
\hline
\end{tabular}

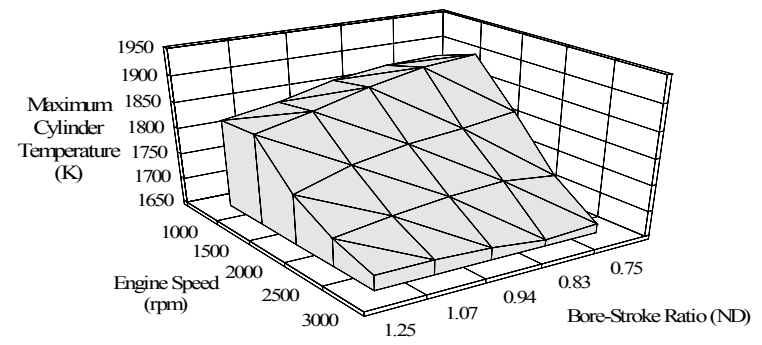

Fig. 5: Variation of peak cylinder temperature with $\mathrm{B} / \mathrm{S}$ ratio at different engine speeds

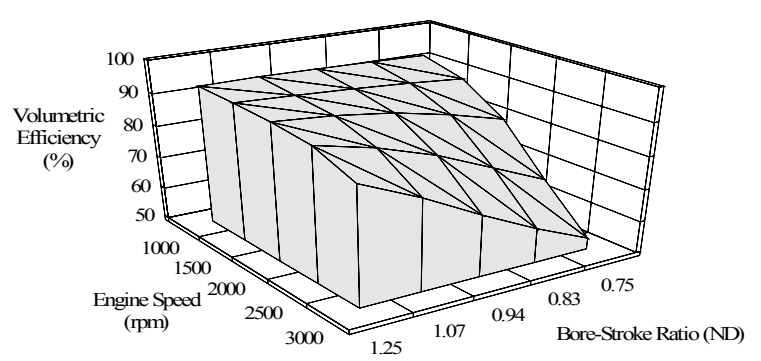

Fig. 6: Variation of volumetric efficiency with B/S ratio at different engine speeds

Figure 1-5 clearly show that the exhaust level of the parameters studied decreased with increasing the bore-to-stroke (hereinafter referred to as $\mathrm{B} / \mathrm{S}$ ) ratio compared with those levels of the original engine setup. This reduction was significant at medium (about 2000 rpm) to high speed (up to $3000 \mathrm{rpm}$ for this engine). Further noticed from the curves is that the exhaust emissions are higher for lower $\mathrm{B} / \mathrm{S}$ ratios and are lower for larger $\mathrm{B} / \mathrm{S}$ ratios.

Expressing these findings in terms of percentages, the effect of changing the $\mathrm{B} / \mathrm{S}$ ratio at higher engine speed $(3000 \mathrm{rpm})$ is shown in the Table 2.

Table 2 clearly shows that using larger stroke lengths (i.e. reducing the $\mathrm{B} / \mathrm{S}$ ratios) at higher speeds is

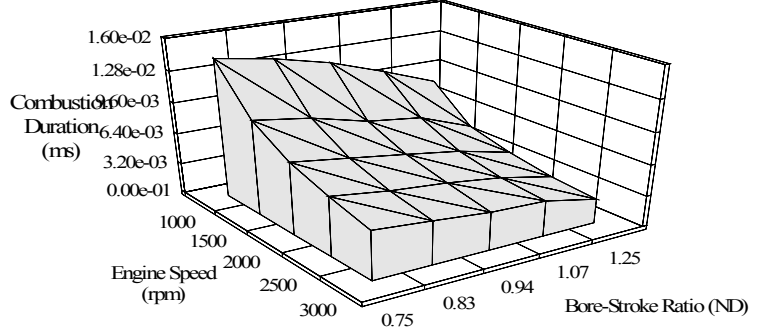

Fig. 7: Variation of combustion duration with $\mathrm{B} / \mathrm{S}$ ratio at different engine speeds

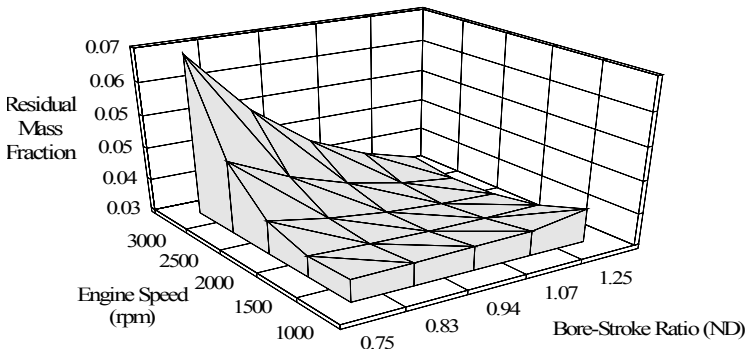

Fig. 8: Variation of residual mass fraction with $\mathrm{B} / \mathrm{S}$ ratio at different engine speeds

not favorable. It also shows the continuous improvement in the carbon-related emissions (e.g. CO2, PM and smoke level) as the stroke length is reduced (within the range studied). On the other hand, NOx behave in an opposite manner and continuously increases as the $\mathrm{B} / \mathrm{S}$ ratio increases, while $\mathrm{NO} 2$ decreases.

A similar table was also constructed at the engine's nominal speed of $1500 \mathrm{rpm}$. This is shown in Table 3.

As seen in the Table 3, the level of variations is less sensitive with respect to higher speeds. Further, the NOx emissions decreased with $\mathrm{B} / \mathrm{S}$ ratio increase, a trend which is opposite to that at higher speeds.

These figures can be well understood with the help of Fig. 6-9. The increased cylinder temperature for 


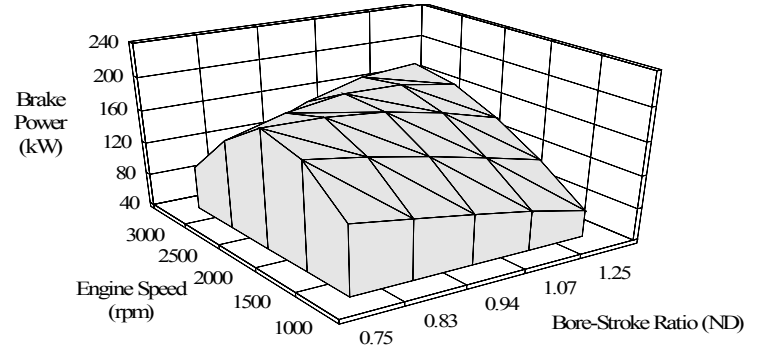

Fig. 9: Variation of brake power with $\mathrm{B} / \mathrm{S}$ ratio at different engine speeds

lower $\mathrm{B} / \mathrm{S}$ ratio up to medium speed (Fig. 6) as a result of relatively higher volumetric efficiency (Fig. 7) and the larger retention time of exhaust products inside the cylinder (Fig. 8) added to it the relatively less concentration of residual fraction (Fig. 9), all caused the brake power of the engine to increase within this range of speed (Fig. 10), hence reduced the specific exhaust emissions.

On the other hand, as the engine speed increases, all the above scenario changes such that the maximum cylinder temperature decreases, as a result of the drastic reduction in the volumetric efficiency and increase in the amount of mass fraction of residuals, all of which has adverse effect on the combustion process. This causes the power of the engine to drop sharply as shown in the figures.

Finally, another look at Fig. 1-5 shows that a reduction of about $10 \%$ to $75 \%$ was achieved for specific particulate matter over the entire speed range. Further, for the case of Bosch smoke number, a reduction of about $10 \%$ to $58 \%$ was achieved for the same speed range. As for the case of carbon dioxide, a reduction of $0 \%$ to $35 \%$ was achieved. On the other hand, a less percent change was achieved for the case of nitrogen dioxide and nitrogen oxides as shown in the figures.

\section{CONCLUSION}

* From the above results, keeping in mind that the main aim of this study was to investigate the effect of varying the stroke length on CI engine exhaust emissions. It can be concluded that:

* There is a niticeable effect of the variable stroke technique on the exhaust emission levels of the CI engine.

* The variable stroke technique helped curbing the diesel exhaust emissions and making the engine more environmentally friendly.

* The engine's specific particulate matter, specific carbon dioxide and Bosch smoke number was significantly reduced at higher $\mathrm{B} / \mathrm{S}$ ratios for all engine speeds within the range studied.

* Larger $\mathrm{B} / \mathrm{S}$ ratios caused the engine power to reduce for low-to-medium speed and increase for higher engine speeds.

* Though larger $\mathrm{B} / \mathrm{S}$ ratios look to have tempting effect on exhaust emissions, however, more research must be done on its large effect on other design parameters.

* For the Bosch smoke number, a reduction of about $10 \%$ to $59 \%$ was achieved for the same speed range.

* Carbon dioxide level was reduced from $0 \%$ to $37 \%$ within the speed range studied.

Appendix A: Data used for computation Engine data

Cycle $\quad:$ 4-Stroke

No of Cylinders $\quad: 6$

Cylinder Bore $\quad: 150 \mathrm{~mm}$

Ratio of crank radius to rod length $\quad: \quad 0.281$

Stroke Length : variable

Compression Ratio $\quad: 15: 1$

Angle of Injection $\quad: 20^{\circ} \mathrm{BTDC}$

Fuel data: Diesel

Fuel Specification (mass ratio) : C (0.87) H (0.126) O (0.004)

Calorific Value $(\mathrm{MJ} / \mathrm{Kg}) \quad: \quad 42.5 \mathrm{MJ} / \mathrm{kg}$

Molecular Weight $\quad: 190 \mathrm{~kg} / \mathrm{kmol}$

Cetane Number : 45

Density : $825 \mathrm{~kg} / \mathrm{m}^{3}$

Specific Vaporization Heat $\quad: \quad 250 \mathrm{MJ} / \mathrm{kg}$

\section{REFERENCES}

1. Kajitani, S. and M. Nakayama, 1998. Possibilities and problems of diesel engine operated with DME. Jidosha Hijutsu, 52: 49-55.

2. Huzayyen, A.S., A.H. Badawy, M.A. Rady and A. Dawood, 2004. Experimental evaluation of diesel engine performance and emission by using blends of jojoba oil and diesel fuel. Energy Conversion and Management, 45: 2093-2112.

3. Altin, R., S. Cetinkaya and H.S. Yucesu, 2001. The potential of using vegetable oil fuels as fuel for diesel engines. Energy Conversion and Management, 42: 529-538.

4. Machacon, H.T.C., Y. Matsumoto, C. Ohkawara, S. Shiga, T. Karasawa and H. Nakamura, 2003. The effect of coconut oil and diesel fuel blends on diesel engine performance and exhaust emissions. Jap. Soc. Automotive Eng. Rev., 22: 349-355. 
5. Nadeema, M., C. Rangkutib, K. Anuarb, M.R.U. Haqc, I.B. Tana and S.S. Shah, 2006. Diesel engine performance and emission evaluation using emulsified fuels stabilized by conventional and gemini surfactants. J. Fuel, 85: 2111-2119.

6. Siegla D.C. and R.M. Siewert, 1978. Variable stroke engine - problems and promises. SAE Trans. No. 780700, 87: 3637-3651.

7. Siewert, R.M., 1978. Engine combustion at large bore-to-stroke ratios. SAE Trans. No. 780968, 87: 2726-2736.

8. Freudenstein, F. and E.R. Maki, 1981. Variable displacement piston engine. U. S. Patent \# 4, 270, 495.

9. Yamin, J.A. and M.H. Dado, 2004. Performance simulation of a four-stroke engine with variable stroke-length and compression ratio. Appl. Energy., 77: 447-463.

10. Filipi, Z.S. and D.N. Assanis, 2000. The effect of the stroke-to-bore ratio on combustion, heat transfer and efficiency of a homogeneous charge spark ignition engine of given displacement. Intl. J. Engine Res., 1: 191-208.
11. Abenavoli, I.R., V. Naso, T. Rychter and A. Teodorczyk, 1990. First experimental analysis of an internal combustion engine with variable stroke and compression ratio. Proc. 25th Intersociety Energy Conversion Engineering Conf., 2: 198-203.

12. Abenavoli, I.R., A. Sciaboni and W. Wardzinski, 1991. Performance analysis of a variable stroke reciprocating engine. Proc. Intersociety Energy Conversion Engineering Conf., 5: 304-307.

13. Kuleshov, A.S., 2005. Model for predicting air-fuel mixing, combustion and emissions in DI diesel engines over whole operating range. SAE Paper No. 2005-01-2119.

14. Pulkrabek, W., 2003. Engineering Fundamentals of the Internal Combustion Engine. Prentice Hall, 2nd Edn. 